\title{
Using Match Rolling Average Periods to Adjust the Conditional Exertion of Soccer Players During Small-Sided Games
}

\author{
Miguel Ángel Campos Vázquez ${ }^{1}$ and Manuel Lapuente Sagarra*2,3,4 \\ ${ }^{1}$ Pablo de Olavide University, Spain \\ ${ }^{2}$ Development \& Innovation on Conditioning \& Exercise (DICFE) Research Group, Inefc Lleida, Spain \\ ${ }^{3}$ Faculty of Sports Science, European University of Madrid, Spain \\ ${ }^{4}$ Analysis Department, Spanish Track \& Field Royal Association, Spain
}

Received: 阱 August 09, 2018; Published: 此 August 14, 2018

*Corresponding author: Manuel Lapuente Sagarra, Development \& Innovation on Conditioning \& Exercise (DICFE) Research Group, Inefc Lleida, Lleida Spain

\section{Introduction}

Soccer is an intermittent sport in which actions performed at high speeds $[1,2]$ take place with other efforts that demand highintensity accelerations and decelerations $[3,4]$, interspersed with low-intensity activities [5] or variable recovery pauses [6]. One concern in the field of training is determining whether the demands of the competition are replicated during training drills. At present, soccer coaches often use in their training programs drills such as small-sided games (SSG) to reproduce the physical, technical and tactical requirements of the competition [7]. These drills should be designed to expose the player to the intensity and load values reached during matches, since performance could be further improved when the training stimuli simulate the physiological demands and movement patterns of competitive matches [8]. Previous investigations have analysed the differences between the physical demands of competitive matches and different SSG proposals $[9,10]$.

The results of these studies concluded that although the SSGs have the potential to expose players to an average intensity similar to that of the competition (relative distance, meters per minute), the high-speed demands reached during matches are usually greater than in SSGs [9]. However, it seems that the accelerative demands could be higher during the SSG [10]. One criticism that can be made of this type of analysis is that we are comparing the average values of drills, usually lasting between two and ten minutes, with the average values reached by players in 90 minutes of competition. This comparison seems questionable, especially when, on numerous occasions, these drills are designed with the aim of exposing players to a training stimulus of intensity similar to the most demanding conditional exertion phases of the competition.0n the other hand, it is important to define which signals or intensity signals should be used to adequately identify the intermittency of the activity carried out, determined by the alternation of actions and pauses and their main characteristics of intensity, duration and type of activity [11].

In this sense, over the past few years researchers have proposed monitoring the heart rate, speed, acceleration and even lately the metabolic power, as the intensity signals reflecting each of them different characteristics of the analysed activity. New proposals that help to overcome the limitations inherent in using the above metrics, however, are going to appear, including mechanical power, accelerometry, electromyography, EMG or others.

Logically, using one or more intensity signals will condition the results of the analysis on the conditional exertion demonstrated in the different temporary windows used.

\section{Worst-Case Scenarios}

Rolling Average Periods: Although assessing these more demanding phases of matches has long been a research target [12-14], we are now starting to obtain reliable information about the demands of these periods. Previous research conducted with professional soccer players tried to identify those more demanding phases of the competition by quantifying the distance covered by the players in pre-established time blocks (temporary windows) ranging from one to 15 minutes [15,16]. However, using preestablished temporary windows could underestimate the peaks of running demands in competitive matches by $20 \%-25 \%$, compared with using rolling techniques (distance covered in a pre-established time, but assessed at any time point, or rolling average periods) [17]. 
This underestimation of the most demanding phases of the competition is due to the fact that the period of highest activity (e.g., time between minutes seven and 12) does not match any of the pre-established time windows (for example: 0-5 minutes, 5-10 minutes, 10-15 minutes). Therefore, the rolling techniques could be more appropriate in describing the most demanding phases of the competition [18]. Thus, using these rolling average procedures, Delaney et al. [18] provided us with invaluable information, showing the magnitude of the most demanding phases of the competition, when they is analysed in temporary windows ranging from one to ten minutes. The results of this study showed that the peak distance run per minute of participation (distance/minute) ranged between $\sim 175 \mathrm{~m} \bullet \mathrm{min}-1$ for periods of one minute and $\sim 123 \mathrm{~m} \bullet \mathrm{min}-1$ for periods of ten minutes, while the metabolic power peak [19] ranged from $\sim 18 \mathrm{w} \bullet \mathrm{kg}-1$ (one minute) to $\sim 12 \mathrm{w} \bullet \mathrm{kg}-1$ (ten minutes).

\section{Practical Applications}

The values shown by Delaney et al. [18] can be a good reference point in designing training drills. In this sense, it is important to emphasise that in replicating the most demanding phases of the competition, the designed drill should reach an intensity level similar to that registered during competition, but in the time window of equal duration of the training drill. For example, for an SSG of 2 vs 2 + goalkeeper, with a duration of two minutes per set, the reference would be the competition temporary window of two minutes. Future research could assess the requirement of matches in even smaller time windows (less than one minute). The maximum intensity shown by the players in short periods of time could be used as a reference to program different proposals of high intensity interval training [19], such as sprint interval training $(\backsim 30$ seconds per effort), or repeated sprint training (approximately six seconds for effort). Our research group was able to confirm that the requirement of competition in the shortest time windows, among professional soccer players, increases to $\backsim 52 \mathrm{w} \bullet \mathrm{kg}-1$ for temporary windows of 6 seconds and $\sim 27 \mathrm{w} \bullet \mathrm{kg}-1$ for temporary windows of 30 seconds (Figure 1), with significant differences across specific positions. However, it is necessary to confirm these results in future investigations.

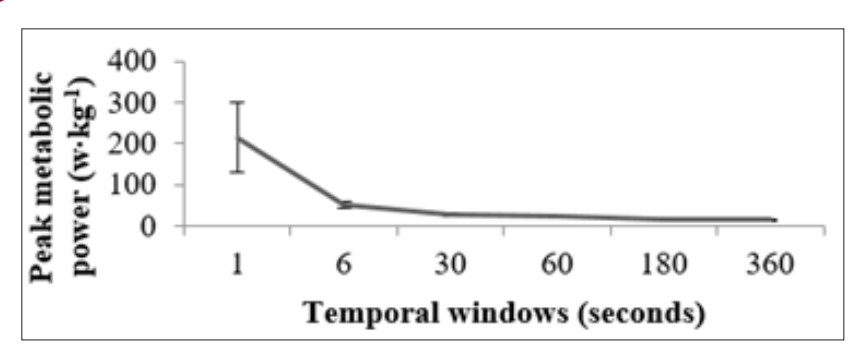

Figure 1: Metabolic power peak $(\mathrm{w} \bullet \mathrm{kg}-1)$ during official competition matches in professional soccer players, in different time windows (1-360 seconds).

\section{References}

1. Di Salvo V, Baron R, Gonzalez-Haro C, Gormasz C, Pigozzi F, et al. (2010) Sprinting analysis of elite soccer players during European Champions League and UEFA Cup matches. J Sports Sci 28(14): 1489-1494
2. Di Salvo V, Gregson W, Atkinson G, Tordoff P, Drust B (2009) Analysis of high intensity activity in Premier League soccer. Int J Sports Med 30(3): 205-212

3. Osgnach C, Poser S, Bernardini R, Rinaldo R, di Prampero PE (2010) Energy cost and metabolic power in elite soccer: a new match analysis approach. Med Sci Sports Exerc 42(1): 170-178

4. Mascherini G, Cattozzo A, Galanti G, Fiorini S (2014) Kinematic profile in elite soccer. Int J Sports Sci 4(6A): 42-48.

5. Bloomfield J, Polman R, O'Donoghue P (2007) Physical Demands of Different Positions in FA Premier League Soccer. J Sports Sci Med 6(1): 63-70

6. Siegle M, Lames M (2012) Game interruptions in elite soccer. J Sports Sci 30(7): 619-624.

7. Aguiar M, Botelho G, Lago C, Macas V, Sampaio J (2012) A review on the effects of soccer small-sided games. J Hum Kinet 33: 103-113.

8. Sampaio J, Abrantes C, Leite N (2009) Power, heart rate and perceived exertion responses to $3 \times 3$ and $4 \times 4$ basketball small-sided games. Rev Psicol Dep 18: 443-467.

9. Casamichana D, Castellano J, Castagna C (2012) Comparing the physical demands of friendly matches and small-sided games in semiprofessional soccer players. J Strength Cond Res 26(3): 837-843.

10. Castellano J, Casamichana D (2013) Differences in the number of accelerations between small-sided games and friendly matches in soccer. J Sports Sci Med 12(1): 209-210.

11. Buchheit M, Laursen PB (2013) High-intensity interval training, solutions to the programming puzzle: Part I: cardiopulmonary emphasis. Sports Med 43(5): 313-338.

12. Mohr M, Krustrup P, Bangsbo J (2003) Match performance of highstandard soccer players with special reference to development of fatigue. J Sports Sci 21(7): 519-528.

13. Bradley PS, Di Mascio M, Peart D, Olsen P, Sheldon B (2010) Highintensity activity profiles of elite soccer players at different performance levels. J Strength Cond Res 24(9): 2343-2351.

14. Bradley PS, Carling C, Archer D, Roberts J, Dodds A, et al. (2011) The effect of playing formation on high-intensity running and technical profiles in English FA Premier League soccer matches. J Sports Sci 29(8): 821-830.

15. Bradley PS, Sheldon W, Wooster B, Olsen P, Boanas P, et al. (2009) Highintensity running in English FA Premier League soccer matches. J Sports Sci 27(2): 159-168.

16. Lacome M, Simpson BM, Cholley Y, Lambert P, Buchheit M (2018) SmallSided Games in Elite Soccer: Does One Size Fit All? Int J Sports Physiol Perform 13(5): 568-576.

17. Varley MC, Elias GP, Aughey RJ (2012) Current match-analysis techniques' underestimation of intense periods of high-velocity running. Int J Sports Physiol Perform 7(2): 183-185.

18. Delaney JA, Thornton HR, Burgess DJ, Dascombe BJ, Duthie GM (2017) Duration-specific running intensities of Australian Football match-play. J Sci Med Sport 20(7): 689-694.

19. Di Prampero PE, Fusi S, Sepulcri L, Morin JB, Belli A, et al. (2005) Sprint running: a new energetic approach. J Exp Biol 208(14): 2809-2816. 


\section{ISSN: 2574-1241}

DOI: $10.26717 / B J S T R .2018 .08 .001583$

Manuel Lapuente Sagarra. Biomed J Sci \& Tech Res

(c) (i) This work is licensed under Creative

Submission Link: https://biomedres.us/submit-manuscript.php

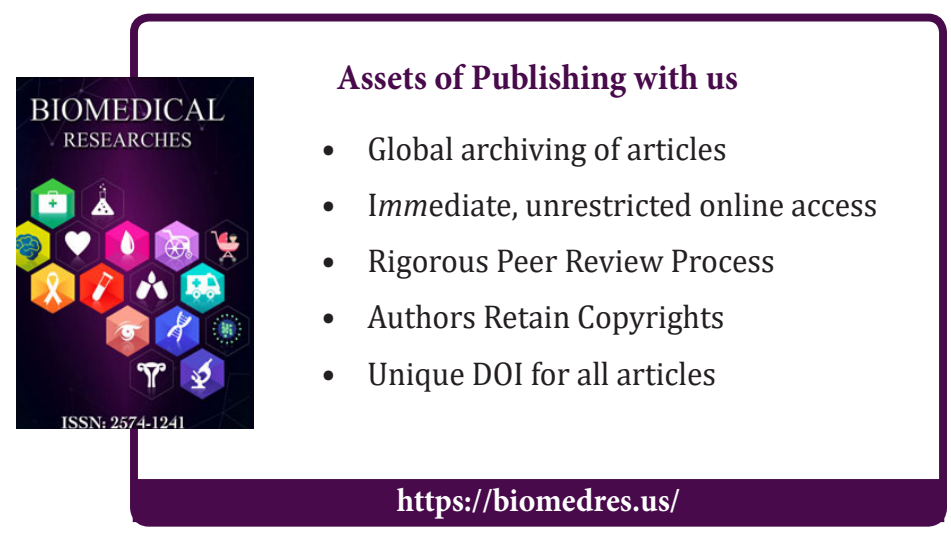

